\title{
Obesity plans must tackle common enemy driving decay
}

The British Dental Association (BDA) has welcomed the government's push on obesity but warned that ministers must confront the common factors driving record numbers of tooth extractions among children.

The BDA has been a vocal advocate for sweeping change to food display and marketing, including measures the government has pledged to consult on, such as the end of buy-one-get-one-free promotions and junk food ads, and clarity on food and drink labelling. It has said the government must double down with a common risk factor approach.

Tooth decay remains the number one reason for hospital admissions among young children in the UK. The latest Public Health England survey of oral health of five-year-olds showed a ten-fold difference in the severity of dental decay between those in more and less deprived local authority areas.

The BDA anticipates the pandemic will increase this already unacceptable disparity, thanks to lockdown diets, the suspension of public health programmes working on the prevention of tooth decay, and high street practices now running at less than a quarter of their former capacity.

Dentist leaders have said the government must make creating a healthy food environment to support good choices a top priority, stressing that a reliance on individual responsibility will only drive further inequalities. It has called for further action on the extension of the successful sugar levy, and swift implementation of energy drinks ban for kids. It has also cautioned that any end to TV ads must not enable the industry to colonise new media.

The BDA has also stressed the necessity of parallel action, including follow up on policies that were championed in last year's green paper on prevention, such as supervised brushing in schools.

BDA Chair Mick Armstrong said:

'The government has a historic opportunity to put its money where its mouth is when it comes to prevention, but it must take a joined-up approach.

'It will be negligence if this war on obesity does not confront the common enemy driving an oral health crisis.

'The time must mark the beginning and not the end of government's willingness to step up and confront these grotesque inequalities. We look to ministers for decisive action, and not let this vital agenda die a death by a thousand consultations.' 